\title{
Exploring Oral English Learning Motivation in Chinese International Students with Low Oral English Proficiency
}

\author{
Deyu (Cindy) Xing \\ Benjamin Bolden \\ Queen's University, Canada
}

\begin{abstract}
This study employed narrative inquiry to understand the oral English learning motivation of Chinese international students with low oral English proficiency through their academic acculturation stories. Expectancy-value theory served as the theoretical framework to inform the study design and the interpretation of results. Findings suggest all participants' motivation for oral English learning increased as a result of the newly acquired high subjective value of spoken English during their academic acculturation. However, they experienced high levels of psychological stress during their academic acculturation due to their low oral English proficiency. Further, participants' perceived expectancy of success for learning oral English declined as their academic acculturation progressed, negatively influencing their oral English learning motivation. Implications for various stakeholders are discussed.
\end{abstract}

Keywords: academic acculturation, Chinese students, expectancy-value theory, oral English learning motivation

In our current age of globalization, it is common practice for North American universities to actively recruit international students (Tang, Collier, \& Witt, 2018), as they bring benefits such as enhanced campus diversity, increased employment opportunities within the local economy, and university revenue (Zhang \& Beck, 2014). Meanwhile, students are keen to seek out international education opportunities, hoping for academic and social experiences that will help them secure a brighter future (Elliot, Reid, \& Baumfield, 2016). 
One key prerequisite for international students' admission into English-speaking institutions is their English language proficiency. Long after admission, however, language proficiency continues to play a significant and influential role in international students' academic acculturation (Sawir, Marginson, Forbes-Mewett, Nyland, \& Ramia, 2012), because it is a salient stressor that interacts with other stressors in both academic and nonacademic settings (C. P. Chen, 1999; Leong, 2015). Among the four skills of language proficiency, speaking is particularly important, because it affects international students' ability to engage academically and socially (Leong, 2015; Poyrazli \& Kavanaugh, 2006; Yeh \& Inose, 2003).

With respect to international students' ability to engage socially, studies have shown that the number of host culture friends that international students have in a new social environment is a major factor for them to acculturate successfully (Hong, Fox, \& Almarza, 2007), and that the inability to fluently speak the host language is a primary inhibiter for international students to develop intercultural friendships (Meng, Zhu, \& Cao, 2018). International students who can communicate fluently in oral English have a higher sense of connectedness to English-speaking surroundings and lower cultural stress when compared with other international students with limited oral English capacity (Rosenthal, Russell, \& Thomson, 2006).

Chinese international students, the biggest international student body worldwide (G. Li, Chen, \& Duanmu, 2010; Meng et al., 2018), often demonstrate low oral English communication capacity and face harsh academic acculturation realities in English-speaking countries (Zhang \& Beck, 2014). Among the commonly identified academic acculturation stressors-language proficiency, educational and sociocultural differences, discrimination, and practical stressors (Smith \& Khawaja, 2011) - language proficiency has been identified as the biggest barrier for successful academic acculturation (Yi, 2004; Zhang \& Beck, 2014). Exclusion from host culture communities has emerged as a prominent theme in the academic acculturation experiences of Chinese international students with limited oral English proficiency (Zhang \& Beck, 2014). Given the continuously increasing number of Chinese international students worldwide and the often-reported stressful academic acculturation experiences of Chinese international students, there is an ongoing need to further explore the factors that influence Chinese international students' academic acculturation (Meng et al., 2018).

Even though language proficiency has been emphasized in academic acculturation research, language learning motivation of international students prior to and during their academic acculturation remains largely unexamined (Chirkov, Safdar, de Guzman, \& Playford, 2008); the psychological mechanisms involved in language learning motivation have not been sufficiently studied. Specifically, how the oral English learning motivation of Chinese international students varies prior to and during their academic acculturation remains unclear. Empirical understanding of individual language learning motivation factors is critical in order to better understand and support Chinese international students' academic acculturation processes.

To address the research gap, we designed this study to explore the academic acculturation experiences and oral English learning motivation of Chinese international students who pursue postsecondary education overseas. Specifically, this qualitative research sought to understand the oral English learning motivation of 
six Chinese international students with low oral English proficiency, studying at a mid-sized Canadian university where English is the language of instruction, through their academic acculturation stories. With the term "academic acculturation stories," we refer to the participants' detailed accounts of their experiences living and learning in an unfamiliar overseas academic context. Aligned with this purpose, we derived two research questions: (a) What are the academic acculturation stories of Chinese international students with low oral English proficiency? (b) How do these students describe their motivation for learning oral English in relation to their academic acculturation experiences?

We designed the study to contribute to the existing understanding of international students' academic acculturation in two ways: (a) by adding to the body of academic acculturation literature through an in-depth narrative inquiry focusing specifically on the academic acculturation experiences of Chinese international students with low oral English proficiency; and (b) by expanding current understanding of international students' motivation for oral English learning prior to and during academic acculturation in English-speaking countries.

\section{THEORETICAL FRAMEWORK}

\section{Expectancy-Value Theory}

In the field of psychology, learning behaviors are often examined with reference to expectancy-value theory (Xie \& Andrews, 2012). Expectancy-value theory proposes that the motivation behind an individual's choice to perform an activity can be explained in relation to two factors: (a) their expectancy of success with the activity and (b) the value they attach to the activity (Wigfield \& Eccles, 2000). In an academic context, expectancy of success is related to students' beliefs about their capability to perform a given task (Schunk, 1991). When assigned a task, students ask themselves: "Can I do it?" Subjective value is the degree to which an individual deems the task to be worth doing (Jacobs \& Eccles, 2000); students ask themselves: "Do I want to do it?" (Eccles \& Wigfield, 2002). How students answer these two questions affects their motivation to engage in the task. If the answer to both is "yes," students are likely to be motivated to engage in the task; if the answers to both questions is "no," then students will not be motivated to engage in the task (Eccles \& Wigfield, 2002).

Expectancy of success and value are two useful factors to consider in seeking understanding of Chinese international students' behavioral choices with regard to their oral English learning. In light of expectancy-value theory, we first look at literature related to the value factor of Chinese international students' motivation for oral English learning, and then move on to their expectancy of success in relation to oral English learning.

\section{The Objective Value of Oral English and Academic Acculturation}

Oral English proficiency profoundly influences international students' academic acculturation. In this study, international students are defined as "linguistically and culturally diverse students engaging with the academic study cultures of English- 
medium universities" (Cheng \& Fox, 2008, p. 309). According to Cheng and Fox (2008), academic acculturation is a complex and idiosyncratic interplay between academic and nonacademic experiences that is related to language proficiency. Oral language proficiency is particularly relevant to international students' ability to engage socially, and social engagement is crucial; a positive relationship exists between social contact with the host culture through oral communication and successful academic acculturation (Cheng \& Fox, 2008; Glass \& Westmont, 2014; Zimmermann, 1995). Among English language skills, speaking is significant in affecting intercultural friendship development (Hong et al., 2007). In turn, the number of host national friends an international student has in the new environment is a major factor for successful acculturation (Hong et al., 2007).

Despite clear evidence that oral English proficiency has high objective value in relation to international students' academic acculturation success, the perceived subjective value of oral English proficiency amongst students in China is different.

\section{The Subjective Value of Oral English in Chinese English Education}

Within Chinese English education, the oral component of English language learning is not perceived as important as reading, writing, and listening. China's English language testing system reflects this lack of importance. All of the language tests focus solely on assessing reading and writing (Cheng, 2008). It was not until 1999 that a spoken English subtest was developed based on Bachman and Palmer's theoretical framework of language test design (H. Li, 1999). However, unlike the listening, reading, and writing components of the test, the speaking test is optional, is only available to a small number of students (those who score high in preliminary tests), and is not a requirement for Chinese postsecondary graduation ( $\mathrm{H}$. Li, 1999).

The washback of these testing practices diminishes the perceived subjective value of oral English proficiency among Chinese students. Washback is a term widely used in language testing, referring to the influence testing has on teaching and learning (Xie \& Andrews, 2012). In China, the washback of English language testing is severe. Teaching to the test has been a common practice throughout the whole country for decades (He \& Shi, 2011). Concerns about washback identify the negative influences of teaching to the test, which include a narrowed curriculum and the downplaying of practical language ability (Qi, 2005). When oral English proficiency is not tested, it is not valued in English teaching, either in schools or after-school test preparation centers (Y. Li, 2014). Consequently, having been immersed in an English language-teaching context that does not value oral communication, students do not recognize the value of oral English proficiency.

Chinese students are only required to take English language proficiency tests that have a compulsory speaking component when they decide to pursue international higher education. Two common measures of English language proficiency are the Test of English as a Foreign Language (TOEFL) and the International English Language Testing System (IELTS). Both TOEFL and IELTS have a speaking component that is valued equally with the listening, reading, and writing components, accounting for one fourth of the global test score. However, because many Chinese students have already been acculturated to the belief that speaking is not an important 
component of academic English language learning (He \& Shi, 2011), they still perceive training in reading and writing as more important. In fact, Zhang and Beck (2014) identified a popular belief among Chinese parents, teachers, and students that the ability to speak English proficiently will simply materialize soon after the students arrive and begin their studies in an English-speaking country.

Therefore, despite the extremely high objective value of oral English proficiency in relation to supporting the success of international students in universities where English is the medium of instruction, the perceived subjective value of oral English proficiency remains low among Chinese students in China. There exists a huge gap between the subjective value and objective value that Chinese international students ascribe to oral English proficiency before they actually begin their overseas study. Hence, the answer to the "Do I want to do it?" question for learning oral Englishaligning with students' low valuing of oral English-is likely to be "no."

\section{Expectation of Success for Learning Oral English among Chinese Students}

In addition to the low subjective value Chinese students tend to attribute to oral English proficiency, a low expectancy of success contributes to their lack of motivation for oral English learning prior to overseas studies. Due to the aforementioned washback on English language teaching in China, teachers and students teach and learn to the test, making passing the test the ultimate goal (Jin, 2015). As oral English proficiency does not play any significant role in helping students to pass the tests, test preparation focuses almost exclusively on reading and writing. Consequently, Chinese students learn English in an environment devoid of oral English (He \& Shi, 2011) and are not exposed to adequate oral English training, even in such basic aspects as pronunciation (He \& Shi, 2011). Often Chinese students speak English with a strong accent that severely influences effective communication with native English speakers, making them feel apprehensive when speaking in English (He \& Shi, 2011). It is often the case that Chinese students spend up to a decade in English language learning contexts being trained only in reading and writing (Jin, 2015). When they are eventually required to speak in order to obtain the required TOEFL/ IELTS test scores for international education admission, they feel very insecure about their speaking and tend to perceive themselves as more capable in doing the reading and writing test components. To compensate, students often further minimize their oral training to focus on achieving higher reading and writing scores, in the hope they will counter-balance the low oral language grades in the global test score.

As a result of these factors, Chinese students tend to have a low expectancy of success in relation to learning oral English. This low expectation of success is negatively related to their motivation. In other words, when a Chinese student is given an oral English task, and asks both "Can I do it?" and "Do I want to do it?", the answer to both questions is likely to be "no." According to expectancy-value theory, when the answers to both questions are "no," students will not be motivated to engage (Eccles \& Wigfield, 2002).

It is not surprising, then, that Chinese international students tend to lack motivation for learning oral English prior to their international education, and it is 
also not surprising that, compared with other international students, Chinese international students demonstrate lower oral English communication capacity (G. Li et al., 2010). Unfortunately, as a result of their limited oral English, Chinese international students are more likely to experience acculturative stress and psychological problems than other international students (J. A. Chen et al., 2015; G. Li et al., 2010). However, it remains unclear how Chinese international students' academic acculturation experiences impact their motivation in oral English learning once they realize what it is like to have limited oral English proficiency in an Englishspeaking academic context. Hence, we designed the study reported here to explore motivation for oral English learning among Chinese international students with low oral English proficiency, through the academic acculturation stories they relate.

\section{METHODS}

In alignment with our purpose and research questions, we structured the study as a narrative inquiry (Clandinin, 2000). Narrative inquiry is effective for understanding and representing human experiences because "the storied descriptions people give about the meaning they attribute to life events is the best evidence available to researchers about the realm of people's experience" (Polkinghorne, 2007, p. 479). Narrative inquiry enables understanding through inquiring "how people think through events and what they value" (Riley \& Hawe, 2005, p. 229). Narrative inquiry suited the general objective of the study: to gain understanding of the motivational factors at play in the complex experiences told by Chinese international students with low oral English proficiency.

\section{Participants and Recruitment}

We recruited participants from a mid-sized Canadian university where English is the language of instruction. We required that participants were Chinese students attending university classes. We contacted the university's international center and English school to distribute the recruitment email to all Chinese international students attending the university. We also utilized snowball sampling through our personal contacts to facilitate the recruitment. In the recruitment notice we asked participants to self-identify as students with low oral English proficiency. Then, when potential participants contacted us, we asked them to provide their original admission TOEFL/IELTS scores to verify their speaking scores. If their speaking scores were at or below the minimum requirement for admission into the university's undergraduate program, the students were invited to participate. Often international students are offered conditional acceptance to an institution even though their language scores fall below the minimum requirements, with the condition that certain language courses be completed before or together with the program of study.

Because the fundamental aim of narrative inquiry is to gain an in-depth understanding of individuals' experiences through collecting and analyzing detailed individual narratives of experience, as opposed to generalizability (Lieblich et al., 1998), we decided to carry out multiple data collection sessions with a small number of individuals. The small sample size enabled the capture of detailed stories while 
still allowing for a variety of participant experiences to be represented (Creswell, 2005). We continued to recruit participants until we reached data saturation (Morse, 1995) with our sixth participant. Data saturation is the point at which significant information across participants' data becomes repetitive, and no new salient information is identified (Morse, 1995).

\section{Data Collection}

We used a predetermined interview protocol to elicit data directly relevant to answer the research questions (Leins et al., 2014). The interview protocol was designed following an interview protocol refinement framework comprised of a fourphase process: "(1) ensuring interview questions align with research questions, (2) constructing an inquiry-based conversation, (3) receiving feedback on interview protocols, and (4) piloting the interview protocol" (Castillo-Montoya, 2016, p. 811).

We first developed interview questions around the research questions of this study informed by expectancy-value theory. We designed questions in three main categories: (a) the academic acculturation experiences participants experienced, (b) their value and expectancy of success for learning oral English before and during their academic acculturation, and (c) how their academic acculturation experiences impacted their value and expectancy of success for learning oral English in Canada. Then we further condensed and refined all questions to be open-ended to invite an inquiry-based conversation, as the aim of in-depth interviewing is not to get answers to questions but to understand the complex individual lived experiences of people (Seidman, 2013). Following these steps, two experts in qualitative research methods reviewed the protocol to generate feedback for further revision as a quality control measure. Finally, the first author translated the questions into Chinese and tried the interview questions with Chinese English as a foreign language speakers to ensure the wording was concise.

The first author, who is proficient in both Chinese and English, conducted the interviews in Chinese because the participants were, of necessity, low in oral English proficiency. It was important for participants to use the language with which they felt most comfortable and were most likely to be successful in communicating the full richness of their experiences. While following the general format of the interview protocol, the first author followed it with flexibility, so that the conversations were appropriate for capturing the unique voices and experiences of each participant (Rabionet, 2011).

One preliminary and one follow-up in-person interview were conducted with each participant. Follow-up interviews were conducted after the preliminary analysis of the first interview data to further probe emergent themes from the first interview. Each interview lasted 45-60 min, and was audio-recorded. Each interview was transcribed by the first author, and the subsequent transcription, in Chinese, was sent to the participant to verify that it accurately captured what they intended to communicate. The verified transcripts were then translated into English by the first author for analysis. 


\section{Data Analysis}

Data analysis was carried out in two stages. First, in keeping with narrative inquiry methods, we analyzed the data through the process of re-storying (Creswell, 2005). We organized the experiences described by each participant in their interviews into a narrative sequence to form an independent personalized story, to describe and illuminate, in their own words, each individual's lived experience of academic acculturation. Second, we used a general inductive analysis approach (Thomas, 2006). Working across the re-storied narratives, we identified text segments significant to the research questions, labeled (coded) the text segments, and then organized related codes and data into themes. Initial codes and themes were generated by the first author. The second author then reviewed the data and coding to raise questions, suggest alternative interpretations, and discuss possibilities for organizing and presenting findings. This negotiation continued until consensus was reached.

\section{FINDINGS}

In this section we report findings in relation to our two research questions: (a) What are the academic acculturation stories of Chinese international students with low oral English proficiency? (b) How do these students describe their motivation for learning oral English in relation to their academic acculturation experiences?

\section{Academic Acculturation Stories of Chinese International Students with Low Oral English Proficiency}

Through the processes of narrative re-storying (Creswell, 2005) and general inductive analysis (Thomas, 2006), it became apparent that the academic acculturation stories of the six participants in this study were penetrated with four overarching themes: (a) excitement and shock, (b) pain and anxiety, (d) loneliness and isolation, and (e) helplessness and resignation. Although the magnitude of these psychological responses varied among the six participants due to individual differences, all these responses were present and significant in each of the participants' stories.

\section{Excitement and Shock}

The theme of excitement and shock refers to the high hopes and optimistic outlook participants held for their international education journey before their arrival in Canada and the unexpected discrepancy between their hopes and reality. The theme was prevalent in all six participants' narratives.

The participants described positive feelings when they first arrived in Canada stemming from high expectations for their overseas study experience and an optimistic outlook regarding communicating in English. As Kandy framed it, "It's just speaking ABCs. How hard could it be?" This optimistic outlook made them confident and excited about embarking on an international journey of study. The participants also described looking forward to communicating with people from other 
countries and making international friends. Lisa imagined herself "talking and laughing out loud on campus with Canadian friends."

However, once they started using English to communicate in an authentic English-speaking environment, with native English speakers engaging in conversations at normal speed, they were shocked. Kandy repeatedly used the exclamatory phrase, "Oh my God!" when describing her disbelief, while Kevin claimed that "the real English communication in Canada was totally different" from what he had learned in China. All six participants were overwhelmed by the discrepancy between the anticipated reality and the actual reality of English communication in Canada. The excitement Kandy and Kevin had felt for studying abroad was based on false confidence in their English capacities, derived from the praise of their parents and teachers in China who only focused on grades. The realization of their inability to communicate orally in Canada was a grim awakening to the challenges of academic acculturation.

Similarly, before arriving in Canada, Nick and Lisa anticipated "some English communication problems" (Lisa) but were still optimistic. However, as Nick lamented during his first interview, "I never thought the problems would be this insurmountable." Amanda and Selina also underestimated how severely their English oral communication deficiency would negatively impact their experiences. Amanda explained she had thought her "English would be improving very quickly by listening to and speaking English all the time in Canada." However, the reality was very different: "Even after more than a year of study in Canada, I still can't make Canadian friends and speak English with a strong accent." (Selina)

\section{Pain and Anxiety}

Following their preliminary feelings of excitement, and then shock, participants identified pain and anxiety resulting from the communication barriers they encountered during their academic acculturation process both in academic and nonacademic domains.

Participants frequently used the words "frustration," "embarrassment," "shame," and "pain" to describe their feelings while adjusting to a Canadian academic setting. As Nick painfully pointed out, "For a task that took one hour for Canadian students, I would probably need five hours."

While the academic pressure was a little less for Selina and Amanda, in the preparatory language program, the other four in the undergraduate program could not communicate with professors or other Canadian students for help to tackle the academic challenges they faced. Low oral English proficiency resulted in the four participants "working alone and working extra-long hours" (Kandy), leaving them constantly stressed, as Nick explained, "both physically and psychologically.

In addition to frustrations in the academic domain, the participants' nonacademic oral communication experiences were no less frustrating. All six participants experienced barriers dealing with even basic daily life situations such as getting the right food in a restaurant. In the social aspects of their lives, none of them was successful in developing relationships with Canadians because they were "not capable of having in-depth and efficient social conversations in English" (Kevin). As 
Kandy explained, the "heart-wrenching feelings" resulting from her inability to communicate made her feel like "that person in The Scream" (the famous painting by Norwegian Expressionist artist Edvard Munch).

Accompanying the painful feelings resulting from various communication barriers was a strong feeling of anxiety for all six participants. After arriving in Canada, they realized that the English they were taught to speak in China was very different from the authentic colloquial language used by native English speakers. As a result, they became anxious and nervous, because they knew that they were "supposed to participate by speaking English" (Kandy), yet they were "not able to express themselves in English" (Selina). Kandy even got to the point of nervously "tapping her feet whenever sitting in the classroom," while Selina felt "afraid to speak English" with other international students. Nick got so anxious that his "brain would just go blank when talking in English in front of people."

The perceived discrepancy between themselves and other students undermined their confidence, leaving them feeling "somehow not good enough" (Nick), "lame" (Kandy), or "not equal" (Lisa) to the students who could communicate in English freely. Participants constantly compared themselves with Canadian students or international students with high oral English proficiency, leading to a feeling of inferiority, which in return further exacerbated their anxiety when communicating in English.

\section{Loneliness and Isolation}

Finding themselves alone in a foreign country, far removed from their usual social support systems, and separated from the Canadian community due to their inability to communicate in oral English, participants described intense loneliness and isolation.

"Being far away from home all alone" (Kandy) without familiar social supports such as family and friends weighed heavily on the students. Compounding this challenge was the difficulty, due to communication barriers, of connecting with the Canadian community. Because of their low oral conversation capacity, the participants "could not engage in meaningful social conversations" (Amanda). Consequently, they "could not bond with Canadian students" (Kevin), even though all of them felt Canadian students were very welcoming and friendly.

As a result, all six participants perceived themselves as "outsiders" (Kevin). They felt Canada was "not a world of their own" (Nick), and they felt rejected by the host culture community. The feeling of rejection caused them to feel isolated. As Kevin expressed: "Without relationships with the Canadians, no matter how beautiful Canada seemed to be or how well I did academically, I still felt empty inside and alone."

\section{Helplessness and Resignation}

After repeated futile attempts to communicate in English, and failure to access local social supports to provide help or empathy for the psychological stress they were experiencing, participants described feeling helpless and resigned. 
Being international students, all the participants' established support systems, family and friends, were in China. However, even though those support systems were accessible via phone and electronic communication, all participants described feeling that their family and friends in China could not offer the empathy they needed because they "had not lived the academic acculturation experiences" (Kevin). Participants also felt embarrassed to discuss their difficulties with friends in China; Kandy explained that her friends perceived her study abroad to be "colorful and exciting" (Kandy), and she did not want to have to explain the reality to them.

When Selina tried to explain to her parents about the difficulties she was experiencing in Canada, her parents blamed her for not working hard enough. Similarly, Nick eventually chose to lie to his parents by saying his oral English was getting better even though in fact it was "not improving at all," because his parents kept hectoring him as to why he did not converse with Canadian students and improve his English quickly. Other participants withheld the language deficiency difficulties they encountered from their parents out of "fear of disappointing them" and because they were "reluctant to worry them" (Kandy).

Both Kandy and Nick pointed out that they were not able to voice their feelings of frustration to their Chinese friends in Canada either. They were afraid that such conversations would just make things even heavier and more depressing for all of them. In addition, although there were counseling services available through the university, it was no help due to the participants' inability to communicate with the counselors. Four of the six participants clearly stated in the interviews that they needed help from psychological counseling, but they did not feel the service the university offered would be of any use to them. Amanda and Nick were not even aware that campus counseling services were available.

Eventually, after repeated communication frustration, participants gave up trying to find a place in the Canadian community. Instead, the participants only socialized with other Chinese students. As a result, their daily communications always involved speaking Chinese. Despite their recognition that they needed to learn English to study or do "almost everything" (Kandy) in Canada, they chose to speak Chinese out of "communication efficiency" (Kandy) and "avoidance of embarrassment" (Nick). Consequently, they resigned themselves to being separate from the host culture community and "not living in an English-speaking environment" (Nick), even though they were studying in an English-speaking university.

In summary, the academic acculturation stories of the participants in this study clearly demonstrated that, as a result of their limited oral English capacity, they faced constant and significant challenges in the new academic setting. These challenges resulted in a constellation of negative emotional responses. It was evident that the participants' language communication difficulties severely impacted their psychological well-being during their time studying in Canada.

\section{Oral English Learning Motivation in Relation to Academic Acculturation Experiences}

As a result of their extremely difficult academic acculturation experiences in Canada, the participants described increased motivation for enhancing their oral 
English proficiency. In the light of the expectancy-value theory, this increased motivation can be explained by the continually increasing subjective value participants came to attribute to learning oral English. However, expectancy of success also plays a role in motivation. While the expectancy of success for oral English acquisition peaked briefly at the beginning of the students' academic acculturation, when they first arrived in Canada, it soon started to decline as they realized that they would not learn to communicate in English as easily as they had anticipated. For a visual representation of the students' shifting subjective valuing of, and expectancy of success for oral English learning in relation to their academic acculturation experiences, please see Figure 1.

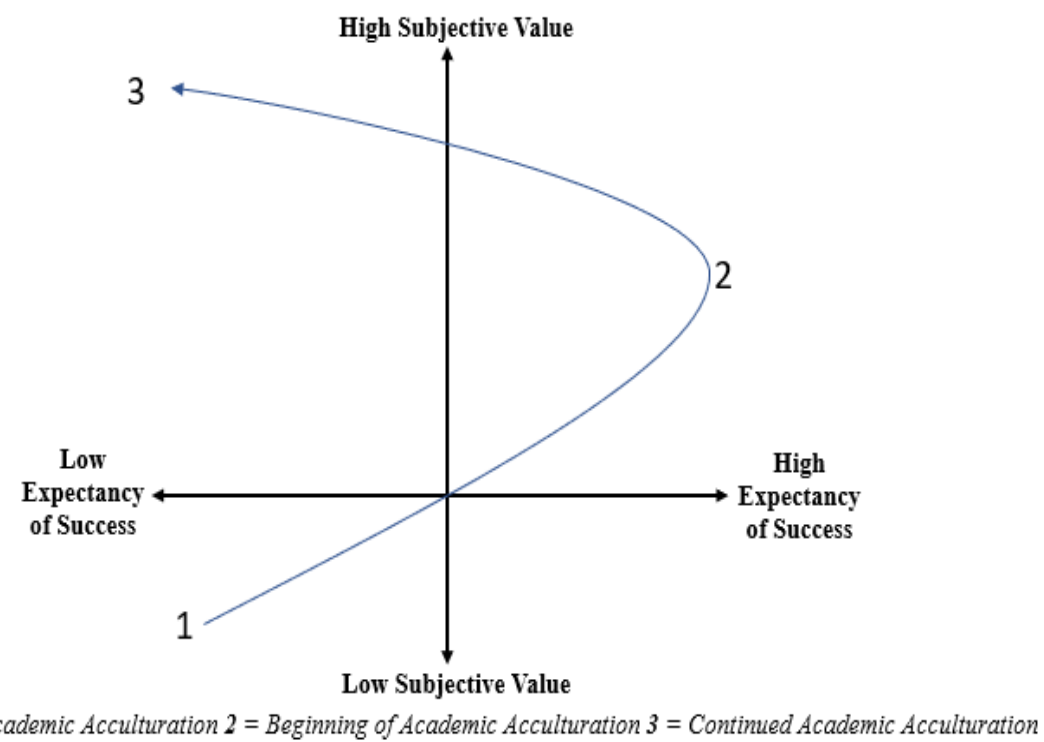

\section{Figure 1: Oral English Learning Motivation in Relation to Academic Acculturation}

The visual representation indicated in Figure 1 was created by the researchers to illustrate the students' shifting subjective valuing of and expectancy of success for oral English learning in relation to their academic acculturation experiences.

\section{Low Subjective Value Before Academic Acculturation}

When asked how they valued oral English before they began their studies in Canada, five of the six participants referred to oral English as "unimportant" because it was not addressed in their English tests. Only Selina, who attended an international high school, thought spoken English was somewhat important. All participants reported that the English teaching and learning they had experienced only focused on material that would be tested in written exams, which confirms the prominent 
washback of English language testing in China (He \& Shi, 2011). As a result, before they arrived in Canada, all six participants assigned little value to the spoken component of English language learning, because it did not figure prominently in the teaching and testing they experienced in China.

Even when these students had to take non-Chinese English proficiency tests that had an oral component, such as IELTS or TOEFL, they still focused on "wordlist memorizing" (Selina) and "test paper drilling" (Amanda) during their preparations. All six participants took IETLS or TOEFL test preparation courses in private tutoring centers, but all the course content heavily "emphasized test-taking skills instead of actual language communication ability" (Lisa). None had any idea that an oral English deficiency could influence their lives so profoundly in an English-speaking country. In short, before their study in Canada, none of the six participants subjectively valued oral English.

\section{Rising Subjective Value of Oral English During Academic Acculturation.}

However, because the participants' inability to communicate orally in English resulted in such harsh academic acculturation experiences, they came to a painful but clear realization that oral English proficiency was vital for their international study. The initial shock that resulted from the inability to "talk like a normal person" (Nick) with native English speakers in daily social settings made participants see the value of oral English that they had not seen before they came to Canada.

After repeated frustrations when engaging in conversations with Canadians, the participants perceived their inability to communicate in oral English as "the biggest gap" (Lisa) between Canadian students and themselves. They recognized that they were not able to express themselves in oral English in an academic context. The recognition of this deficiency subsequently led to acute feelings of anxiety for their academic performance, and inferiority in comparison to the Canadian students surrounding them. As Nick shared,

Lots of project assignments require substantial oral communication with Canadian students, and participation alone accounts for a portion of the final grade. I got very anxious when I found out my roommate received a grade of zero for a group project because he failed to communicate with his Canadian teammates.

When the participants realized the academic stakes associated with oral English communication, they assigned further value to oral English learning in relation to their study in Canada.

As their academic acculturation progressed, the students began to notice that their low oral English proficiency undermined their "life in Canada in every way" (Kandy). This was another reason to assign additional value to oral English learning. As Lisa opined, "Improving oral English is more important than the academic courses." As her acculturation continued, she recognized that her limited oral English not only influenced her academic study but also cost her many other affordances that she used to have in China, such as close personal relationships, leaving her lonely and isolated, 
like a "barren tree that has lost all of its leaves." Again, realizations such as these boosted the students' subjective valuing of oral English learning.

\section{Low Expectancy of Success Before Academic Acculturation}

When asked about the possibility of successfully acquiring a high level of oral English proficiency in China, all six participants described it as impossible. As Selina commented, "My teachers spoke 'Chinglish' with an accent that was totally odd! How good can my spoken English be?" Additionally, all participants identified the lack of authentic English-speaking environment within the Chinese context as a key reason why they were not confident in achieving oral English proficiency in China. Therefore, before they arrived in Canada, while still in China, the participants had a very low expectancy of success for oral English language learning.

\section{Peaked Expectancy of Success at the Beginning of Academic Acculturation}

When all six participants first arrived in Canada, they were very excited to start their journey in an English-speaking environment filled with opportunities to be in contact with native English speakers. The students imagined they would be "speaking to Canadians every day" (Amanda) and "walking with foreign students, boys, and girls all together on campus" (Lisa). This expectation of abundant opportunities to be in contact with authentic English speaking drove their expectancy of success for oral English learning to a high level at the beginning of their academic acculturation.

\section{Decreased Expectancy of Success as Academic Acculturation Progressed}

However, the initial brief excitement of being immersed in an English-speaking environment was soon replaced by shock. Participants were astonished when they discovered the oral English they learned in China was "worlds apart from the English spoken by Canadians" (Kandy). When their "Chinglish" stopped them from having smooth conversations with native English speakers, their excitement at being able to utilize the authentic English-speaking environment to practice and improve their spoken English was dampened. The students' expectancy of success for oral English learning began to diminish.

Increasingly, after continuous communication frustrations and failed attempts to bond and form friendships with Canadians, participants felt rejected by the Canadian community. Lisa realized that "even though Canadian students are all very friendly and nice, they are not going to talk too much with you if you speak English with a very strong accent." Nick explained: "Without the ability to produce clear and fluent oral English speech, it is impossible to make real Canadian friends." The sense that they had been rejected by the Canadian community left the students feeling "lonely," "insecure," and "isolated" in a foreign country. As a result, participants turned to other Chinese-speaking students so they would feel "secure" (Kandy) and "connected" (Nick). The students' expectancy of success for oral English learning decreased further as the students recognized they were isolated from the Canadian community, not able to access authentic English-speaking opportunities. 
Although all six participants continued to desire to integrate into Englishspeaking communities, they felt helpless, because they could not have meaningful conversations with Canadians. The students eventually gave up trying to find a place in the Canadian community and stayed in the Chinese community. This resignation and their daily Chinese-speaking academic acculturation reality continued to diminish their expectancy of success for learning oral English.

The subjective value that these six students attached to oral English proficiency continually increased in relation to their academic acculturation experiences, which positively impacted their oral English learning motivation. In contrast, their expectancy of success only peaked at the very beginning of their academic acculturation process. Their perceived high expectancy of success declined as they encountered repeated communication frustrations and weakened further when they experienced isolation and resigned themselves to communicating only in Chinese with other Chinese international students, which negatively influenced their oral English learning motivation. Overall, due to the extremely high subjective value for oral English proficiency that all six participants acquired over the course of their harsh academic acculturation, all students described an increased motivation for oral English learning.

\section{DISCUSSION}

The data in this study clearly illustrate the positive relationship between oral English proficiency and successful academic acculturation for Chinese international students, as previously identified by Sawir et al. (2012). The Chinese international students with low oral English proficiency suffered severe consequences academically, socially, and emotionally during their academic acculturation process due to their inability to communicate orally, as has also been reported by Zhang and Beck (2014). As a result of their painful academic acculturation experiences, the students' subjective valuing of oral English communication increased, as did their motivation for oral English learning. However, their expectancy of success for oral English learning peaked only at the beginning stage of academic acculturation, and then decreased as they realized they were unable to cultivate meaningful relationships or practice oral communication with English-speaking peers.

It seems commonsensical to reiterate that oral language is perhaps the most critical form of communication for international students and speaking the same language as their host country peers is the best way to communicate. However, this seemingly commonsensical understanding was not held by the participants in this study, who were educated in a context that emphasized the value of silence in classrooms (Sun, 2009; Yang, 2011) and English language learning practices that focused solely on success in test-taking (He \& Shi, 2011; Jin, 2015). The subjective value that the participants ascribed to oral English learning before their academic acculturation in Canada was low. The participants only came to a clear realization of the value of oral English for their international study and became motivated to learn oral English after their painful academic acculturation experiences.

Research indicates that Chinese students tend to have distinctively low motivation during their decade-long English education program in China (He \& Shi, 
2011; Jin, 2015). This lack of motivation contributes to the relatively low oral English proficiency of Chinese students as an international student group (G. Li et al., 2010). Consequently, Chinese international students tend to experience substantial academic acculturation difficulty and psychological stress (Meng et al., 2018). What would help these students?

Expectancy-value theory suggests that recognizing the high value of a learning activity is not sufficient on its own to motivate engagement. Learners also need to have at least a reasonable expectancy of success. To better design and anchor support for international students, it is necessary to understand not only how and why they value oral English for communication and survival but also how and why their motivation for learning oral English might shift before and during academic acculturation. Even though it is common for someone to value a new language as a means of communication in a foreign country, a low expectancy of success such as the participants in this study experienced, resulting from a lack of opportunity to speak with host country peers, will negatively influence their oral English learning motivation and impede their successful academic acculturation. Perhaps, if more accessible social support and better language learning support had been provided at the beginning stage of their academic acculturation-before they began to feel isolated and helpless - the students would not have lost their initial high expectancy of success. With both a high subjective value of oral English learning and a high expectancy of success in place, students would likely have been highly motivated. Accordingly, they would have been better positioned to gain oral English proficiency, and so experience a more successful academic acculturation.

\section{Implications}

The findings have various implications for stakeholders in the Chinese context as well as host country institutions. To support and facilitate successful academic acculturation for Chinese international students in English-speaking countries, there is much that can be done.

\section{Implications for Chinese Students, Parents, Chinese English-Language Educators and Test Designers}

Chinese parents and students need to be made aware of the value of oral English proficiency and the relationship between oral communication and international students' successful academic acculturation. Chinese parents and students are willing to invest in English language education. However, evidence from this study and elsewhere (e.g., Matoush \& Fu, 2012) suggests that Chinese parents and students need to be cognizant of the limitations of test preparation centers and invest more generously in language educational services that emphasize authentic language learning that values speaking alongside listening, reading, and writing. Parents and students can make effective English language education choices only when they understand and recognize the value of oral English proficiency.

In addition, the English testing system (as well as English teaching and learning) in China needs to be enhanced for better testing quality (Cheng, 2008) by the addition 
of a mandatory speaking component. Not only would this addition render the tests more authentic as a measure of a student's English language capacity, but the washback would likely exert a positive influence on English teaching and learning. With the speaking component made mandatory for high-stakes admission and graduation English tests, the firmly entrenched practice of teaching to the test would require the focus of attention to expand from only reading and writing to include speaking.

This study also has implications for English as a second language (ESL) teacher training in China. ESL teachers need specific professional training for teaching the oral component of English, so that they are able to help students communicate in spoken English confidently and effectively and afford students a reasonable expectancy of success. If ESL teachers can only speak "Chinglish," with an accent that severely hinders communication with native English speakers, it is very unlikely that their students will feel confident about achieving oral English proficiency.

\section{Implications for Host Country Academic Institutions and Educators}

Academic institutions should pay particular attention to the design of programs that actively help international students at the beginning of their academic acculturation journey, with targeted oral English language learning support and opportunities to socialize with host country peers (thereby increasing their expectancy of success for oral English learning). Additionally, support services such as academic and personal counseling need to be made accessible throughout the students' programs of study with a foregrounded recognition that low oral proficiency inherently creates a barrier for many international students to access and benefit from such programs.

Meanwhile, educators who work with international students should be made aware of the particular challenges that students with low oral English proficiency face in academic contexts-for example, challenges related to group work, oral presentations, and the inability to confidently articulate questions. It is extremely valuable for institutions to offer ESL language programs to international students with low English proficiency. However, it is key that such programs pay particular attention to supporting oral proficiency-for example, by emphasizing the oftenneglected sound system of the English language to help students develop solid ability and confidence for oral English communication. Research confirms that effective teaching of English pronunciation can make an important difference in helping international students to integrate socially into the host culture (Derwing \& Munro, 2005).

\section{Limitations and Future Research}

Due to the in-depth narrative nature of this study, only six undergraduate Chinese students from one Canadian university were included. The participants represented students in math, engineering, arts, and science, and the English language program. For future research, it would be informative to study the academic acculturation experiences and oral English learning motivation of Chinese international students 
with low oral English proficiency from a variety of universities and include participants from more programs, particularly the business programs whose curricula require substantial oral communication (Brink \& Costigan, 2015).

This research was also limited by its focus on participants with low oral English communication capacity. Additional research that examines how Chinese international students with a high level of English oral communication capacity in English-speaking countries acculturate into their overseas studies would help to further develop understanding of the relationship between oral proficiency and academic acculturation.

\section{CONCLUSION}

Chinese international students, who make up a significant portion of the international student body in English-language academic institutions all over the world (G. Li et al., 2010), often demonstrate low oral English proficiency and so are frequently perceived as "the silent group" on campus, separated from the host culture community (Yi, 2014). However, this study introduced to us that the six Chinese international students with limited spoken English were in fact very eager to communicate with and acculturate into the host culture community. They experienced isolation resulting not from personal choices, but from frequent, often insurmountable, oral communication barriers.

Over the course of their academic acculturation, the participants in this study experienced shock, anxiety, social isolation, and helplessness. Their painful academic acculturation experiences did, to a certain degree, increase the students' motivation for oral English learning as a result of their increased subjective valuing of oral communication in authentic English. However, the grim reality of isolation and helplessness also made them view the goal of speaking fluent and authentic English to acculturate as unrealistic, leading to a low expectancy of success that undermined their motivation.

This research provides insight into the interactions between Chinese international students' oral English proficiency, academic acculturation, and motivation for oral English learning. The understandings gained suggest important implications for enhancing the practices of those involved in the English language education and host institution support of Chinese international students. Students who seek out international study and the institutions who welcome them recognize the potential for both to benefit. This study identifies the importance of supporting international students' successful academic acculturation in order to realize those benefits, how supporting oral English learning can help, and what those supports could look like.

\section{REFERENCES}

Brink, K. E., \& Costigan, R. D. (2015). Oral communication skills: Are the priorities of the workplace and AACSB-Accredited business programs aligned? Academy of Management Learning \& Education, 14(2), 205-221.

Castillo-Montoya, M. (2016). Preparing for interview research: The interview protocol refinement framework. The Qualitative Report, 21, 811-831. 
Chen, C. P. (1999). Common stressors among international college students: Research and counseling implications. Journal of College Counseling, 2, 49-65. doi:10.1002/j.2161-1882.1999.tb00142.x

Chen, J. A., Liu, L., Zhao, X., \& Yeung, A. S. (2015). Chinese international students: An emerging mental health crisis. Journal of the American Academy of Child \& Adolescent Psychiatry, 54, 879-880. doi:10.1016/j.jaac.2015.06.022

Cheng, L. (2008). The key to success: English language testing in China. Language Testing, 25, 15-37. doi:10.1177/0265532207083743

Cheng, L., \& Fox, J. (2008). Towards a better understanding of academic acculturation: Second language students in Canadian universities. Canadian Modern Language Review/ La Revue Canadienne Des Langues Vivantes, 65, 307-333.

Chirkov, V. I., Safdar, S., de Guzman, J., \& Playford, K. (2008). Further examining the role motivation to study abroad plays in the adaptation of international students in Canada. International Journal of Intercultural Relations, 32, 427440. doi:10.1016/j.ijintrel.2007.12.001

Clandinin, D. J. (2000). Narrative inquiry: Experience and story in qualitative research. San Francisco, CA: Jossey-Bass.

Creswell, J. W. (2005). Educational research: Planning, conducting, and evaluating quantitative. Upper Saddle River, NJ: Prentice Hall.

Derwing, T. M., \& Munro, M. J. (2005). Second language accent and pronunciation teaching: A research-based approach. TESOL Quarterly, 39, 379-397. doi: $10.2307 / 3588486$

Eccles, J. S., \& Wigfield, A. (2002). Motivational beliefs, values, and goals. Annual Review of Psychology, 53, 109-132. doi:10.1146/annurev.psych.53.100901.135153

Elliot, D., Reid, K., \& Baumfield, V. (2016). Beyond the amusement, puzzlement and challenges: An enquiry into international students' academic acculturation. Studies in Higher Education, 41(12), 2198-2217. doi:10.1080/03075079.2015.1029903

Glass, C. R., \& Westmont, C. M. (2014). Comparative effects of belongingness on the academic success and cross-cultural interactions of domestic and international students. International Journal of Intercultural Relations 38, 106119.

He, L., \& Shi, J. (2011). 浅析影响大学生英语口语能力的因素及教学策略 [Factor analysis on the Chinese college oral English education]. Science \& Technology Information, 9, 1-8.

Hong, L., Fox, R. F., \& Almarza, D. J. (2007). Strangers in stranger lands: Language, learning, and culture. International Journal of Progressive Education, 3(1), 144.

Jacobs, J. E., \& Eccles, J. S. (2000). Parents, task values, and real-life achievementrelated choices. In C. Sansone \& J. M. Harackiewicz (Eds.), Intrinsic motivation (pp. 405-439). San Diego, CA: Academic Press.

Jin, Z. (2015). 近十年高考英语反驳效应研究综述 [The decade-long washback of Chinese NMET]. Gao Kao, 5, 115-116. 
Leins, D. A., Fisher, R. P., Pludwinski, L., Rivard, J., \& Robertson, B. (2014). Interview protocols to facilitate human intelligence sources' recollections of meetings. Applied Cognitive Psychology, 28, 926-935.

Leong, P., (2015). Coming to America: Assessing the patterns of acculturation, friendship formation, and the academic experiences of international students at a U.S. College. Journal of International Students, 5(4), 459-474.

Li, G., Chen, W., \& Duanmu, J. (2010). Determinants of international students' academic performance: A comparison between Chinese and other international students. Journal of Studies in International Education, 14, 389-405. doi: $10.1177 / 1028315309331490$

Li, H. 1999. Language test development and College English Test -Spoken English Test. Foreign Languages and Their Teaching, 12(6), 28-30.

Li， Y. (2014). 对英语课外辅导班的思考 [Perspectives on English tutoring industry]. Jiao Yu Lun Tan, 9, 242.

Lieblich, A., Tuval-Mashiach, R., \& Zilber, T. (1998). Applied social research methods: Narrative research. Thousand Oaks, CA: Sage.

Matoush, M. M., \& Fu, D. (2012). Tests of English language as significant thresholds for college-bound Chinese and the washback of test-preparation. Changing English, 19(1), 111-121. doi:10.1080/1358684X.2012.649176

Meng, Q., Zhu, C., \& Cao, C. (2018). Chinese international students' social connectedness, social and academic adaptation: the mediating role of global competence. Higher Education, 75(1), 131-147.

Morse, J. M. (1995). The significance of saturation. Qualitative Health Research, 5, $147-149$.

Polkinghorne, D. (2007). Validity issues in narrative research. Qualitative Inquiry, 13, 471-486. doi:10.1177/1077800406297670

Poyrazli, S., \& Kavanaugh, P. R. (2006). Marital status, ethnicity, academic achievement, and adjustment strains: The case of graduate international students. College Student Journal, 40, 767-780.

Qi, L. (2005). Stakeholders' conflicting aims undermine the washback function of a high-stakes test. Language Testing, 22(2), 142-173. doi:10.1191/0265532205lt300oa

Rabionet, S. E. (2011). How I learned to design and conduct semi-structured interviews: An ongoing and continuous journey. The Qualitative Report, 16, $563-566$.

Riley, T., \& Hawe, P. (2005). Researching practice: The methodological case for narrative inquiry. Health Education Research, 20, 226-236.

Rosenthal, D. A., Russell, V. J., \& Thomson, G. D. (2006). A growing experience: The health and the well-being of international students at the University of Melbourne. Melbourne, Australia: The University of Melbourne.

Sawir, E., Marginson, S., Forbes-Mewett, H., Nyland, C., \& Ramia, G. (2012). International student security and English language proficiency. Journal of Studies in International Education, 16, 434-454.

Schunk, D. H. (1991). Self-efficacy and academic motivation. Educational Psychologist, 26, 207-231. doi:10.1080/00461520.1991.9653133 
Seidman, I. (2013). Interviewing as qualitative research: A guide for researchers in education and the social sciences (4th ed.). New York, NY: Teachers College Press.

Smith, R. A., \& Khawaja, N. G. (2011). A review of the acculturation experiences of international students. International Journal of Intercultural Relations, 35, 699 713. doi:10.1016/j.ijintrel.2011.08.004

Sun, Z. (2009). 儒家教育传统的基本特征及其意义 [The characteristics and meaning of Confucianism]. Journal of Shanxi Normal University, 1, 89-90.

Tang, X., Collier, D.A., \& Witt, A. (2018). Qualitative study on Chinese students' perception of U.S. university life. Journal of International Students, 8(1), 151178.

Thomas, D. (2006). A general inductive approach for analyzing qualitative evaluation data. American Journal of Evaluation, 27, 237-246. doi:10.1177/1098214005283748

Wigfield, A., \& Eccles, J. S. (2000). Expectancy-Value Theory of achievement motivation. Contemporary Educational Psychology, 25, 68-81. doi:10.1006/ceps.1999.1015

Xie, Q., \& Andrews, S. (2012). Do test design and uses influence test preparation? Testing a model of washback with Structural Equation Modeling. Language Testing, 30, 49-70. doi:10.1177/0265532212442634

Yang, H. (2011). 沉默课堂”归因分析及改变措施 [The reason behind the “Silent classroom"]. Zhong Deng Zhi Ye Jiao Yu, 5, 15-16.

Yeh, C. J., \& Inose, M. (2003). International students' reported English fluency, social support satisfaction, and social connectedness as predictors of acculturative stress. Counselling Psychology Quarterly, 16, 15-28. doi:10.1080/0951507031000114058

Yi, L. (2004). Learning to live and study in Canada: Stories of four EFL learners from China. TESL Canada Journal, 22(1), 25-43.

Zhang, Z., \& Beck, K. (2014). I came, but I'm lost: Learning stories of three Chinese international students in Canada. Comparative and International Education / Éducation Comparée et Internationale, 43(2), 1-14.

Zimmerman, S. (1995). Perceptions of intercultural communication competence and international student adaptation to an American campus. Communication Education, 44, 321-335.

DEYU (CINDY) XING, MEd, is a recent graduate in the Faculty of Education at Queen's University, Canada. She earned both her BEc and BA at Beijing Foreign Studies University in China prior to Queen's. She has worked in various educational settings, from language education centers to universities. Her current research interests include international students' academic acculturation, second language acquisition, arts-informed research, at-risk youth, child development, and parenting. Email: xing.deyu@queensu.ca

BENJAMIN BOLDEN, PhD, music educator and composer, is an associate professor and the UNESCO Chair of Arts and Learning in the Faculty of Education 
at Queen's University, Canada. His research interests include arts education systems around the world, the learning and teaching of composing, creativity, arts-based research, preservice music teacher education, teacher knowledge, and teachers' professional learning. As a teacher, Ben has worked with preschool, elementary, secondary, and university students in Canada, England, and Taiwan. Ben is an associate composer of the Canadian Music Centre and his compositions have been performed by a variety of professional and amateur performing ensembles. In 2016 he won the Choral Canada Competition for Choral Writing. Ben was editor of the Canadian Music Educator, journal of the Canadian Music Educators' Association/L'Association canadienne des musiciens éducateurs, from 2007-2014. $\mathrm{He}$ is the proud father of three rascally boys. 